OPEN ACCESS

Edited by:

Mikhail Lebedev,

Duke University, USA

Reviewed by:

Robert E. Clark,

University of California, San Diego,

USA

Baojin Ding,

University of Massachusetts Medical School, USA

*Correspondence:

Esther Krook-Magnuson ekrookma@umn.edu

Received: 31 July 2015 Accepted: 02 December 2015 Published: 22 December 2015

Citation: Yu W and Krook-Magnuson E (2015) Cognitive Collaborations: Bidirectional Functional Connectivity Between the Cerebellum and the Hippocampus.

Front. Syst. Neurosci. 9:177. doi: 10.3389/fnsys.2015.00177

\section{Cognitive Collaborations: Bidirectional Functional Connectivity Between the Cerebellum and the Hippocampus}

\author{
Wilson Yu and Esther Krook-Magnuson * \\ Department of Neuroscience, University of Minnesota, Minneapolis, MN, USA
}

There is a growing recognition that the utility of the cerebellum is not limited to motor control. This review focuses on the particularly novel area of hippocampal-cerebellar interactions. Recent work has illustrated that the hippocampus and cerebellum are functionally connected in a bidirectional manner such that the cerebellum can influence hippocampal activity and vice versa. This functional connectivity has important implications for physiology, including spatial navigation and timing-dependent tasks, as well as pathophysiology, including seizures. Moving forward, an improved understanding of the critical biological underpinnings of these cognitive collaborations may improve interventions for neurological disorders such as epilepsy.

Keywords: cerebellum, hippocampus, connectivity, spatial, temporal, epilepsy

\section{INTRODUCTION}

The cerebellum has traditionally been associated with motor control, motor learning, and coordination (Glickstein, 2007; Manto et al., 2012), but it is now often understood to be more broadly involved in cognitive functions as well (Strick et al., 2009; Popa et al., 2014; Taylor and Ivry, 2014). This is supported in part anatomically by the marked expansion of the human cerebellum (Matano, 2001) and the connections it has developed with areas supporting cognition (Leiner et al., 1986, 1989; Weaver, 2005). Notably, recent studies have reported important functional interactions between the cerebellum and the hippocampal formation (Rochefort et al., 2011; KrookMagnuson et al., 2014; Onuki et al., 2015). For instance, while the process of pattern separation has been studied primarily within subregions of the hippocampal formation, it was recently reported that the cerebellum is also actively engaged during pattern separation tasks (Paleja et al., 2014). Conversely, tasks known to be heavily cerebellum-dependent can be significantly influenced by the hippocampus (Hoffmann and Berry, 2009; Wikgren et al., 2010; Hoffmann et al., 2015). A recognition of cerebellar-hippocampal interactions represents a paradigm shift as it challenges us to re-examine traditional notions of spatial and temporal processing and to better appreciate the collaborative efforts involved. Additionally, the broader role of the cerebellum beyond motor control has critical implications for understanding neurological disorders, including autism and epilepsy. Hippocampal-cerebellar interactions in particular may be especially relevant to temporal lobe epilepsy, as discussed later in this review. 


\section{CEREBELLAR-HIPPOCAMPAL CONNECTIVITY: MANY PATHS OF POTENTIAL INFLUENCE}

The relevant connectivity between the cerebellum and hippocampus is not fully understood, in part because there are several potential pathways connecting these structures (Figure 1). The simplest route would be a direct connection. However, the existence of such a route is controversial. Electrical stimulation of the cerebellum can evoke potentials in the hippocampus (reported for cat, rat, and rhesus monkey; Heath and Harper, 1974; Snider and Maiti, 1976; Heath et al., 1978; Newman and Reza, 1979). An anatomical study in cats and rhesus monkey found degenerating fibers in the hippocampus after a lesion of the cerebellar fastigial nucleus (Heath and
Harper, 1974). In chicken, lesion and retrograde tracing studies also suggest a direct pathway from the hippocampal formation to the cerebellum (Liu et al., 2012). Finally, in humans, a direct white matter bundle connecting the hippocampus and cerebellum was recently reported using probabilistic Constrained Spherical Deconvolution tractography (Arrigo et al., 2014). These studies indicate that these structures might have a direct anatomical substrate by which to influence one another.

However, it is important to recognize that the bidirectional influence of the cerebellum and hippocampus on one another need not rely on a direct monosynaptic connection. Once indirect pathways are considered, there are many potential routes connecting these structures (Figure 1). Optogenetic techniques provide the opportunity to selectively manipulate cell types and

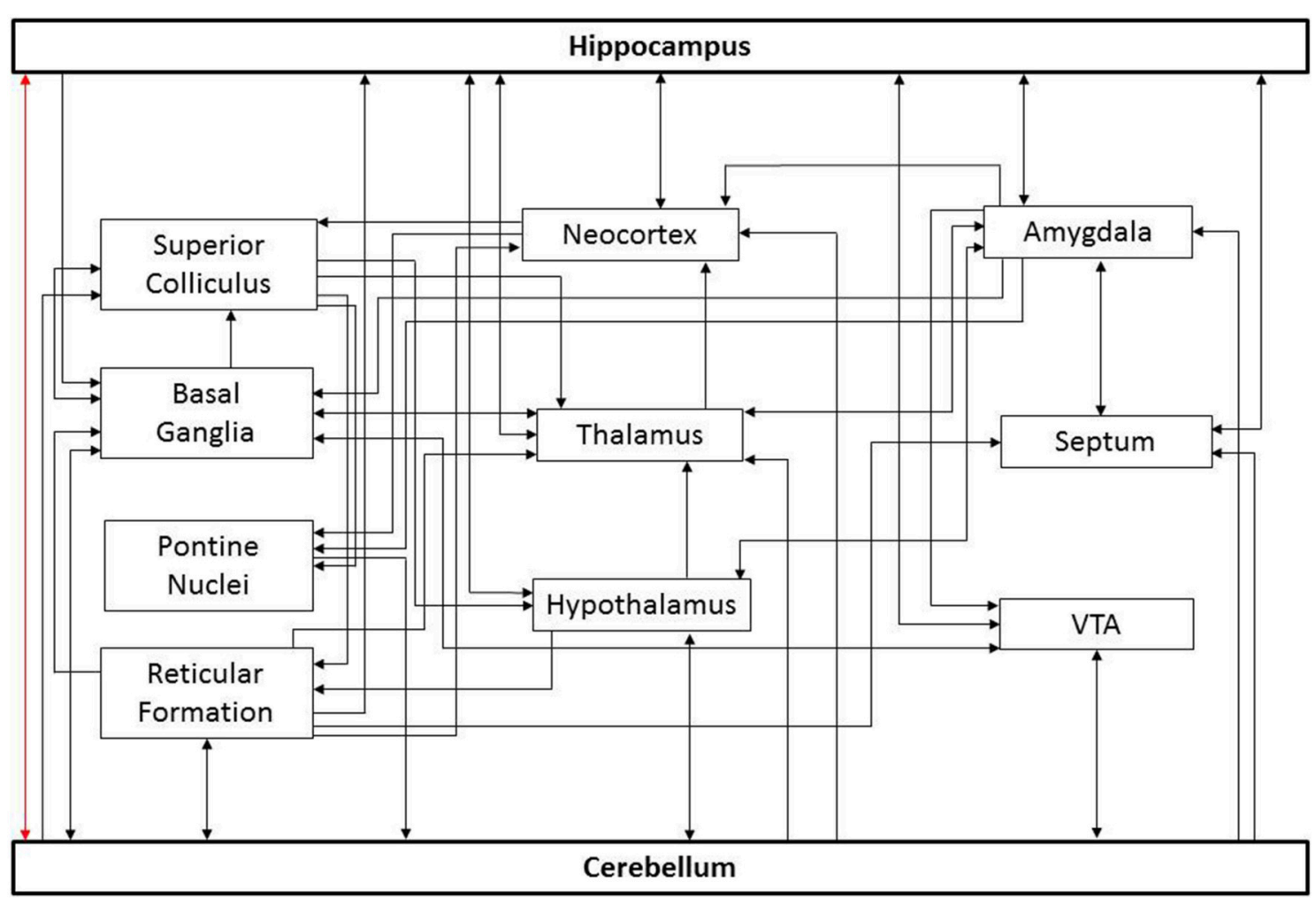

FIGURE 1 | Potential paths of influence. This simplified diagram illustrates potential pathways underlying cerebello-hippocampal functional connectivity. For the sake of simplicity, only general connections between structures are shown; important subdivisions of depicted structures have been omitted. Similarly, only a subset of potential routes is depicted. As noted in the text, there is controversy surrounding a potential direct connection between these structures (red arrow). Additional connections depicted include input to the cerebellum from the basal ganglia (Bostan and Strick, 2010), reticular formation (Pierce et al., 1977; Verveer et al., 1997; Luo and Sugihara, 2014), pontine nuclei (Kawamura and Hashikawa, 1981), hypothalamus (Dietrichs and Haines, 1984, 1986, 1989; Onat and Cavdar, 2003), and ventral tegmental area (VTA) (Snider et al., 1976; Oades and Halliday, 1987); projections from the cerebellum to the superior colliculus (Person et al., 1986a), basal ganglia (Bostan and Strick, 2010), reticular formation (Elisevich et al., 1985; Person et al., 1986b; Perciavalle et al., 1989; Teune et al., 2000; Almeida et al., 2002), hypothalamus (Dietrichs and Haines, 1989; Onat and Cavdar, 2003), thalamus (Haroian et al., 1981; Asanuma et al., 1983; Angaut et al., 1985; Person et al., 1986a), neocortex (Harper and Heath, 1973; Clower et al., 2005), VTA (Oades and Halliday, 1987; Snider et al., 1976), septum (Paul et al., 1973; Heath et al., 1978), and amygdala (Heath and Harper, 1974); projections to the hippocampus from the neocortex (Canto et al., 2008; Ohara et al., 2013), septum (Ohara et al., 2013), reticular formation (Lewis and Shute, 1967; Köhler and Steinbusch, 1982; Andersen et al., 1983), hypothalamus (Lima et al., 2013; Soussi et al., 2015), thalamus (Vertes, 2015), VTA (Kahn and Shohamy, 2013) and amygdala (French et al., 2003); projections from the hippocampus to the amygdala (Ishikawa and Nakamura, 2006), basal ganglia (Floresco et al., 2001), hypothalamus (Swanson and Cowan, 1977), thalamus (Swanson and Cowan, 1977), neocortex (Swanson and Cowan, 1977), VTA (Kahn and Shohamy, 2013), and septum (Swanson and Cowan, 1977). Similarly, connections exist between these intermediate structures which may indirectly influence the cerebellum and hippocampus. 
pathways with temporal precision, and may allow identification of key routes in cerebellar-hippocampal interactions in the future (Boyden et al., 2005; Deisseroth, 2011; Armstrong et al., 2013; Krook-Magnuson and Soltesz, 2015; Krook-Magnuson et al., 2015b). Identifying which of these potential pathways actually play a critical role in the functional connectivity will aid in understanding information processing and may provide additional structures or pathways to target for treating neurological disorders. While there is currently limited data on the pathways mediating cerebellar-hippocampal interactions, it is becoming increasingly evident that they are functionally significant.

\section{CEREBELLAR-HIPPOCAMPAL INTERACTIONS IN SPATIAL PROCESSING}

One of the key functions of the hippocampus is spatial navigation (Eichenbaum, 2000; Dumont and Taube, 2015). However, it does not perform this role in isolation, but rather relies on information input from other brain areas. Studies have demonstrated an important contribution of the cerebellum in the formation of spatial representations (Lalonde and Botez, 1990; Wallesch and Horn, 1990; Petrosini et al., 1998). Spatial navigation involves a combination of internal cues such as proprioceptive and vestibular input, as well as external cues such as landmarks (Dumont and Taube, 2015). The cerebellum receives input from the vestibular nucleus (Hitier et al., 2014) and is believed to play a crucial role in encoding inertial motion and transforming self-motion vestibular information from an egocentric headcentered reference into allocentric Earth-referenced spatial orientation (Yakusheva et al., 2007; Angelaki et al., 2010). Transgenic mice with impaired cerebellar function have deficits in goal-directed spatial trajectories (Burguière et al., 2005), retention of spatial memory (Hilber et al., 1998), and tasks requiring use of self-motion information (Rochefort et al., 2011). The functional connection between the cerebellum and hippocampus in the context of spatial navigation is perhaps most strikingly seen in recordings from hippocampal neurons: animals with certain impairments in cerebellar function have fewer hippocampal place cells, and, when forced to rely on selfmotion cues for spatial navigation, place cells show decreased firing rates and reduced stability (Rochefort et al., 2011). Similarly, in healthy animals, removal of vestibular self-motion cues reduces the number of place cells (Ravassard et al., 2013).

Evidence that the cerebellum is not only important for spatial navigation in rodents, but also in humans, comes from a recent human imaging study which demonstrated functional co-activation of the cerebellum and hippocampus during spatial navigation (Igloi et al., 2014). Interestingly, co-activation was found for both allocentric and egocentric navigation tasks, but with hemispheric specialization. The right cerebellum and left hippocampus displayed coactivation during egocentric navigation, while the left cerebellum and right hippocampus displayed coactivation during allocentric navigation. When both egocentric and allocentric navigation occurred in parallel, both circuits were active. This suggests hemispheric specialization and a potential role for the cerebellum in both egocentric and allocentric navigation.

How does the cerebellum influence hippocampal spatial navigation? One proposal is that the cerebellum provides selfmotion related information to grid cells in the entorhinal cortex (Passot et al., 2012; Rochefort et al., 2013) and thereby contributes to the formation of spatial representations in the hippocampus (McNaughton et al., 2006). However, given the sensitivity of place cells to cerebellar disturbances (Rochefort et al., 2011), and that place cells can exist in the absence of entorhinal cortex grid cells (Bush and Burgess, 2014; Hales et al., 2014), an alternative or additional mechanism seems likely, and there are many possibilities. For example, as head direction cells are able to maintain their firing properties in the dark (at least in animals with a functional cerebellum), they are assumed to receive self-motion cues (Taube, 2007; Bush and Burgess, 2014), and therefore may be influenced by cerebellar function. However, this is only one potential mechanism and further work is needed to determine which of the many possible pathways (Figure 1) are critically involved in cerebellar contributions to spatial processing in the hippocampus.

\section{CEREBELLAR-HIPPOCAMPAL INTERACTIONS IN TEMPORAL PROCESSING}

Just as the cerebellum becomes critical to hippocampal functioning on a hippocampal-dependent task (spatial navigation) when the task requires integration of self-motion cues (a cerebellar forte), the hippocampus can become a vital structure in a cerebellar-dependent task. Specifically, it is well established that the cerebellum is a key structure in conditioned eyeblink responses (Mauk and Thompson, 1987; Moyer et al., 1990; Thompson and Krupa, 1994; Gruart and Yeo, 1995; Kirsch et al., 2003; De Zeeuw and Yeo, 2005; Thompson and Steinmetz, 2009; Longley and Yeo, 2014). Critically, however, when an interval is introduced between the end of the conditioned stimulus and the unconditioned stimulus (i.e., trace eyeblink conditioning), the task (in particular learning of the task, Kim et al., 1995; Takehara et al., 2002, 2003) additionally requires the hippocampus; hippocampal lesions impair the acquisition of trace conditioning responses (Clark et al., 1984; Solomon et al., 1986; Moyer et al., 1990; Clark and Squire, 1998; Ryou et al., 1998; Weiss et al., 1999; Weiss and Disterhoft, 2015). Notably, while the hippocampus plays a central role in spatial navigation, it is also relevant to the coding of time (Eichenbaum, 2014) and, more broadly, declarative and episodic memory (Eichenbaum, 2001; Burgess et al., 2002)—these may be critical functions supplied by the hippocampus to the cerebellum in this task. Despite the cerebellum's hypothesized role in working memory (Kuper et al., 2015), without hippocampal support, the cerebellum appears unable to keep information about the conditioned stimulus "on-line" during the gap between stimuli. Cerebellar cell firing decreases after $\sim 300 \mathrm{~ms}$ (Ito, 1982), and the hippocampus may bridge the gap between the conditioned 
and unconditioned stimulus for the cerebellum. Hippocampal cells have been shown to bridge temporal gaps in other contexts as well, such as during an odor-object pairing task (MacDonald et al., 2011). As in spatial navigation, the dual hippocampal cerebellar dependency of this task has also been demonstrated in humans (Logan and Grafton, 1995; McGlinchey-Berroth et al., 1997). Related to the hippocampus' role in episodic and declarative memory, human studies have further examined the potential need for hippocampal-dependent awareness in the acquisition of trace conditioning (Clark et al., 2002).

It has been proposed that the hippocampal influence on cerebellar function in trace eyeblink conditioning is routed through the medial prefrontal cortex (Figure 1; Weiss and Disterhoft, 2011). However, as dependency on the hippocampus and medial prefrontal cortex show distinct temporal aspects (with the hippocampus rather than the prefrontal cortex being required during learning, Takehara et al., 2003), an alternate route is likely to participate. Interestingly, not only do lesions of the hippocampus disrupt performance on this task (Berry and Thompson, 1979; Solomon et al., 1983), but lesions or inactivation of the cerebellum also disrupts hippocampal responses (Clark et al., 1984; Ryou et al., 1998). This further emphasizes the bidirectional functional connectivity between these two structures, although again, the pathway involved remains unresolved.

The cerebellar interpositus nucleus is crucial in eyeblink conditioning (lesions to this nucleus abolishes conditioned hippocampal responses) and projects conditioned responserelated activity to the red nucleus and the ventral lateral nucleus of the thalamus (Sears et al., 1996). However, lesions to these downstream areas do not affect conditioning-related activity in the hippocampus, indicating additional pathways are likely involved (Clark et al., 1984; Sears and Steinmetz, 1990; Ryou et al., 1998).

A functional coupling between the hippocampus and cerebellum can additionally be seen in the synchronization of oscillations during eyeblink conditioning, as cerebellar and hippocampal type II theta (Bland, 1986) are synchronized during this task (Singer, 1999; Fries, 2005). Strikingly, presentation of a conditioned stimulus will induce theta when an animal is in a non-theta state, induce a phase reset of theta when presented during spontaneous theta, and increase the degree of hippocampal-cerebellar theta synchrony (McCartney et al., 2004; Hoffmann and Berry, 2009; Wikgren et al., 2010; Nokia et al., 2012). Interestingly, in rabbits and humans alike, scopolamine, a competitive muscarinic acetylcholine receptor antagonist known to block type II theta oscillations (Bland, 1986; Buzsaki, 2002), also inhibits eyeblink conditioning (Salvatierra and Berry, 1989; Solomon et al., 1993). Just as elucidating the relevant pathways connecting the hippocampus and the cerebellum is an area for active research, the mechanism behind this theta reset and synchrony across these structures is currently unknown, and may be mediated by a structure which projects to both the hippocampus and cerebellum, rather than indicating a direct cross-talk per se. Potential candidates include the medial septum and the supramammillary nucleus (Figure 1).
The collaborative efforts of the cerebellum and the hippocampus in tasks with a temporal aspect extend beyond eyeblink conditioning. For example, co-activation between the cerebellum and hippocampus is also reported in a recent fMRI study using a finger tapping task (Onuki et al., 2015). Specifically, co-activation between the cerebellum and hippocampus occurs during a version of the task with a spatio-temporal prediction component, but not during similar tasks when prediction is not required. Similarly, as briefly mentioned earlier, the cerebellum and hippocampus were found to be part of a domain-general pattern separation network, active in both spatial and temporal variations of a delayed match-to-sample task (Paleja et al., 2014).

These studies illustrate the growing support for cerebellarhippocampal collaborations in healthy physiology. These interactions may also be important in pathophysiology, and we turn now to a recently highlighted example: temporal lobe epilepsy.

\section{CEREBELLAR-HIPPOCAMPAL INTERACTIONS IN EPILEPSY}

The hippocampal formation is the primary focus in mesial temporal lobe epilepsy, which is the most common adult form of epilepsy and also the most drug-resistant (Wiebe, 2000). Though apparently extremely rare, the cerebellum can be the site of origin for seizures in other forms of epilepsy (Harvey et al., 1996; Mesiwala et al., 2002). Studies have revealed a dynamic interplay between the cerebellum and hippocampus during temporal lobe seizures (Figure 2). Remarkably, hippocampal epileptiform activity modulates cerebellar activity, including the firing of juxtacellularly recorded Purkinje neurons (Figure 2F; Mitra and Snider, 1975; Krook-Magnuson et al., 2014). This is true even for spontaneous seizures arising in the chronic stage of the disorder, following an initial insult directly targeting the hippocampus (and not the cerebellum), for example in the intrahippocampal kainate model of temporal lobe epilepsy (Krook-Magnuson et al., 2014; Figure 2F). Importantly, seizures can modify cerebellar activity without, or prior to, generalization; the modification of cerebellar activity does not simply reflect global seizure effects. Additionally, during the secondary generalization of partial seizures originating from the temporal lobe, single photon emission computed tomography (SPECT) indicates that there is a robust increase in blood flow in the cerebellum (Blumenfeld et al., 2009), and after prolonged status epilepticus neuronal cell loss has been observed in both the hippocampus and cerebellum (Tan and Urich, 1984; Soffer et al., 1986; Leifer et al., 1991).

Just as the interactions during information processing appear to be bidirectional, so too are interactions during seizures; not only do temporal lobe seizures alter cerebellar activity, cerebellar activity can also alter temporal lobe seizures. Again, this indicates a unique position of the cerebellum; not all locations within the brain can have an effect on temporal lobe seizures. For example, directly inhibiting granule cells in the dentate gyrus in the hippocampal formation contralateral to the seizure focus does not significantly alter on-going seizures (Krook-Magnuson et al., 2015a). However, while early studies examining electrical 
A
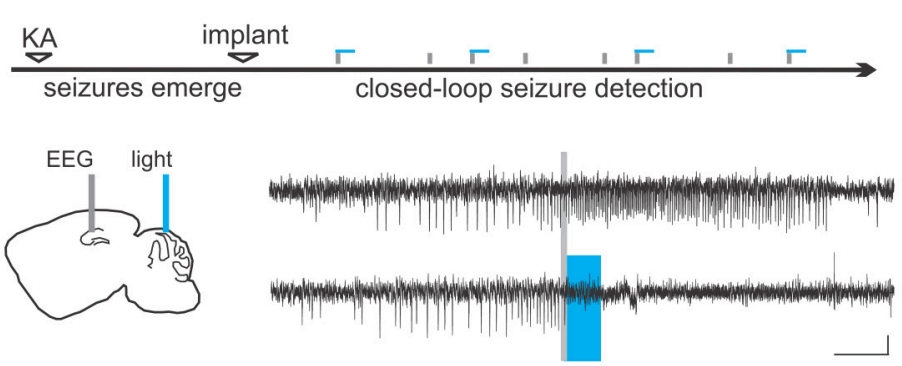

B
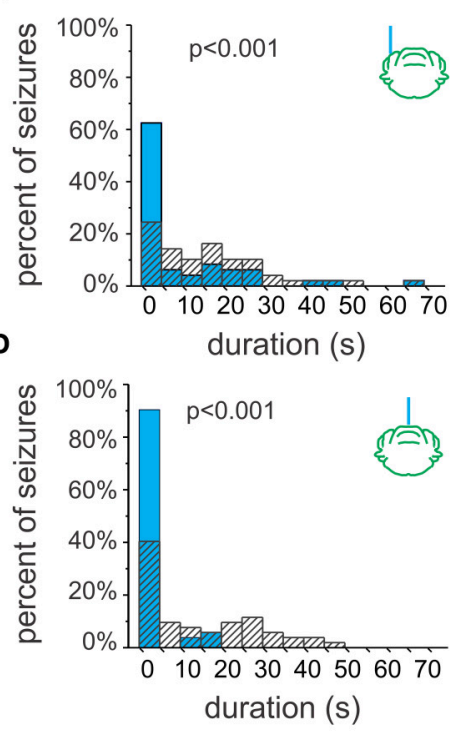

C
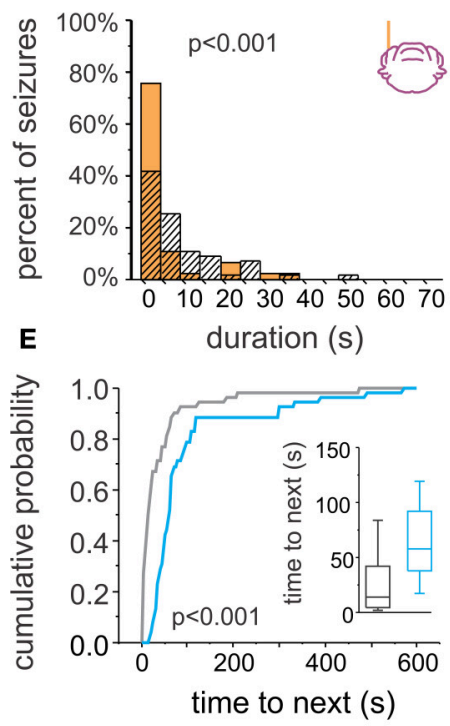

$\mathbf{F}$

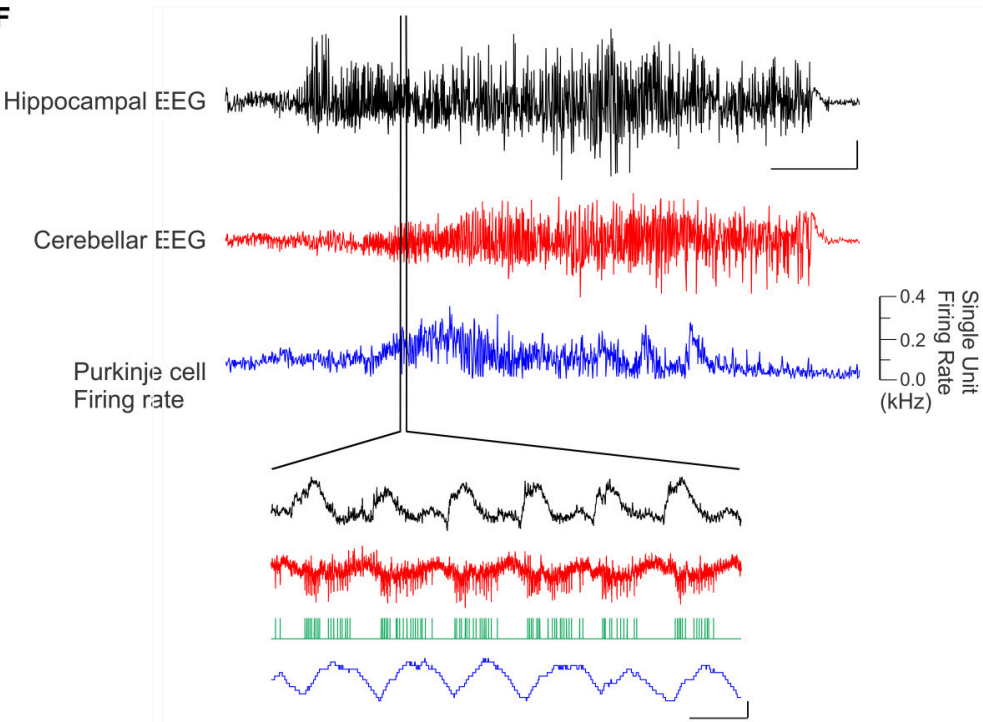

FIGURE 2 | Bidirectional cerebellar-hippocampal connectivity in epilepsy. (A) Intrahippocampal kainate injection induced chronic epilepsy and spontaneous seizures. Seizures were detected online, allowing on-demand optogenetic cerebellar modulation selectively at the time of seizures. Top electrophysiological trace is representative of a detected (gray line) seizure recorded from the hippocampus not receiving optogenetic modulation; bottom trace shows attenuation of hippocampal seizure activity resulting from optogenetic cerebellar modulation (horizontal bar indicates light delivery). Stimulation (B) or inhibition (C) of neurons in the lateral cerebellum or midline vermis (D) significantly reduced hippocampal seizure duration. Vermal stimulation uniquely also significantly increased the time to next seizure, indicating a decrease in seizure frequency (E). (F) Hippocampal seizure activity (black trace) produced changes in the cerebellar EEG (red trace) and modulated the firing rate of Purkinje cells (blue trace), supporting the bidirectional nature of functional connectivity between the cerebellum and hippocampus. Scale bars: (A) $5 \mathrm{~s}$, $0.05 \mathrm{mV}$; (F) Top three traces: $10 \mathrm{~s}$; hippocampal EEG: $1 \mathrm{mV}$, cerebellar EEG: $0.5 \mathrm{mV}$. Lower traces: $0.5 \mathrm{mV}$ or $0.1 \mathrm{kHz}$ change in firing rate, $0.1 \mathrm{~s}$. Reproduced with permission from Krook-Magnuson et al. (2014). 
stimulation of the cerebellum found promising inhibitory effects on seizures (Cooke and Snider, 1955; Babb et al., 1974; Maiti and Snider, 1975), and clinical trials were initiated (Cooper et al., 1973, 1976), electrical stimulation of the cerebellum was ultimately shown to have mixed effects on seizures (Cooper, 1973; Sramka et al., 1976; Van Buren et al., 1978; Levy and Auchterlonie, 1979; Wright et al., 1984; Davis and Emmonds, 1992; Chkhenkeli et al., 2004; Velasco et al., 2005). Therefore, despite the initial enthusiasm for the cerebellum as a potential target for epilepsy intervention, interest has dropped (for a review, see Fountas et al., 2010).

However, a recent study using more modern techniques with improved specificity of intervention supports renewed interest in this area. Using closed-loop on-demand optogenetics to modulate cerebellar Purkinje cells selectively at the time of seizures, the authors found that hippocampal seizures could indeed be inhibited (Figure 2; Krook-Magnuson et al., 2014). Remarkably, through the use of excitatory and inhibitory light sensitive opsin proteins, it was shown that either excitation (Figure 2B) or inhibition (Figure 2C) of the cerebellum could significantly decrease hippocampal seizure duration. This reduction in seizure duration was found whether the midline (vermis) or the lateral (simplex) cerebellum was targeted with light intervention (Figure 2D). However, stimulation (but not inhibition) of the midline vermis (but not the lateral cerebellum) was capable of also reducing the frequency of spontaneous seizures (Figure 2E). Highlighting the uniqueness of this finding, studies using on-demand optogenetic intervention directly targeting the hippocampus did not find a reduction in seizure frequency (Krook-Magnuson et al., 2013, 2014, 2015a). The promising anti-epileptic results from this study using ondemand optogenetic modulation of the cerebellum support the interpretation that the variable efficacy seen in earlier studies could be due to the lack of temporal and/or cell-type specificity of non-on-demand electrical stimulation.

Importantly, the findings described above suggest that the bidirectional influence between the cerebellum and hippocampus has clinical significance for epilepsy research and treatment. However, just as the circuits involved in the cerebellarhippocampal interactions discussed in previous sections are still not resolved, more studies are needed to identify the pathways underlying cerebellar-hippocampal interactions in epilepsy. It is important to also note that while cerebellar-hippocampal interactions in temporal lobe epilepsy are striking, they are not necessarily unique. For example, cerebellar neurons can also fire rhythmically and phase-locked with spike and wave discharges in thalamocortical absence epilepsy (Kandel and Buzsáki, 1993), and transgenic mice primarily lacking P/Q-type calcium channel function in Purkinje cells exhibit absence epilepsy (Mark et al., 2011). Additionally, a recent study showed that pharmacological or optogenetic stimulation of the cerebellar nuclei attenuates the generalized spike-and-wave discharges associated with absence epilepsy (Kros et al., 2015). The cerebellum has also been shown to exert influences on neocortical seizures, as electrical stimulation of the cerebellum has shown both beneficial and negative effects on focal seizures of the neocortex (Miller, 1992). As cerebellar effects on seizures are not limited to seizures originating from the hippocampus, a broad mechanism of action beyond simple, direct, hippocampal-cerebellar interactions may be at play (e.g., potentially via brain state regulation).

While closed-loop optogenetic modulation of specific brain areas and circuits could potentially be implemented clinically in the future (Krook-Magnuson and Soltesz, 2015; KrookMagnuson et al., 2015b), the cerebellum may not be an ideal target for neuroprosthetics. Identifying the mechanism and pathways underlying cerebellar-hippocampal interactions in epilepsy (and the cerebellum in epilepsy more broadly) will therefore provide much needed new potential targets for epilepsy treatment. Additionally, identification of pathways and mechanisms underlying cerebellar-hippocampal interactions may have implications for neurological disorders beyond epilepsy, as the cerebellum has been implicated in a range of disorders, including attention deficit hyperactivity disorder, mood disorders, dyslexia, tinnitus, schizophrenia, and autism spectrum disorders (for a review, see Phillips et al., 2015). For example, fMRI studies indicate reduced cerebellar-hippocampal interactions in schizophrenia (Collin et al., 2011; Duan et al., 2015). While the many potential pathways for the cerebellum and the hippocampus to influence each other presents an initial investigative challenge, they may provide fruitful avenues for intervention in neurological disorders.

\section{CONCLUSIONS}

Although, the idea of a broader role for the cerebellum in cognitive functions remains somewhat controversial, there is a growing recognition of its contributions beyond motor learning and control. Fundamentally, recognizing cerebellar-hippocampal interactions means acknowledging the collaborative nature of cognitive processes and appreciating the potential consequences and opportunities this provides. Recent studies establish the importance of cerebellar-hippocampal functional connectivity for spatial and temporal processing and demonstrate the clinical significance of this interaction. However, despite these functional studies, it remains unclear which pathways are critically involved in these interactions. Once elucidated, the specific pathways mediating cerebellar-hippocampal interactions could potentially be targeted for clinical applications.

\section{ACKNOWLEDGMENTS}

This work was supported by a MnDrive Post-doctoral Fellowship in Neuromodulation (to WY), MnDrive Neuromodulation Scholar Funds (to EK), and a National Institutes of Health grant (R00 NS087110, to EK). The authors would also like to thank two lab members, Zachary Zeidler and Isabelle Febvre, for aiding in the editing of this paper. 


\section{REFERENCES}

Almeida, A., Cobos, A., Tavares, I., and Lima, D. (2002). Brain afferents to the medullary dorsal reticular nucleus: a retrograde and anterograde tracing study in the rat. Eur. J. Neurosci. 16, 81-95. doi: 10.1046/j.1460-9568.2002.02058.x

Andersen, E., Rigor, B., and Dafny, N. (1983). Electrophysiological evidence of concurrent dorsal raphe input to caudate, septum, habenula, thalamus hippocampus, cerebellum and olfactory bulb. Int. J. Neurosci. 18, 107-115. doi: 10.3109/00207458308985884

Angaut, P., Cicirata, F., and Serapide, F. (1985). Topographic organization of the cerebellothalamic projections in the rat. An autoradiographic study. Neuroscience 15, 389-401. doi: 10.1016/0306-4522(85)90221-0

Angelaki, D. E., Yakusheva, T. A., Green, A. M., Dickman, J. D., and Blazquez, P. M. (2010). Computation of egomotion in the macaque cerebellar vermis. Cerebellum 9, 174-182. doi: 10.1007/s12311-009-0147-z

Armstrong, C., Krook-Magnuson, E., Oijala, M., and Soltesz, I. (2013). Closedloop optogenetic intervention in mice. Nat. Protoc. 8, 1475-1493. doi: $10.1038 /$ nprot.2013.080

Arrigo, A., Mormina, E., Anastasi, G. P., Gaeta, M., Calamuneri, A., Quartarone, A., et al. (2014). Constrained spherical deconvolution analysis of the limbic network in human, with emphasis on a direct cerebello-limbic pathway. Front. Hum. Neurosci. 8:987. doi: 10.3389/fnhum.2014.00987

Asanuma, C., Thach, W. T., and Jones, E. G. (1983). Distribution of cerebellar terminations and their relation to other afferent terminations in the ventral lateral thalamic region of the monkey. Brain Res. 286, 237-265. doi: 10.1016/0165-0173(83)90015-2

Babb, T. L., Mitchell, A. G. Jr., and Crandall, P. H. (1974). Fastigiobulbar and dentatothalamic influences on hippocampal cobalt epilepsy in the cat. Electroencephalogr. Clin. Neurophysiol. 36, 141-154. doi: 10.1016/00134694(74)90151-5

Berry, S. D., and Thompson, R. F. (1979). Medial septal lesions retard classical conditioning of the nicitating membrane response in rabbits. Science 205, 209-211. doi: 10.1126/science. 451592

Bland, B. H. (1986). The physiology and pharmacology of hippocampal formation theta rhythms. Progr. Neurobiol. 26, 1-54. doi: 10.1016/0301-0082(86)90019-5

Blumenfeld, H., Varghese, G. I., Purcaro, M. J., Motelow, J. E., Enev, M., McNally, K. A., et al. (2009). Cortical and subcortical networks in human secondarily generalized tonic-clonic seizures. Brain 132, 999-1012. doi: 10.1093/brain/awp028

Bostan, A. C., and Strick, P. L. (2010). The cerebellum and basal ganglia are interconnected. Neuropsychol. Rev. 20, 261-270. doi: 10.1007/s11065-0109143-9

Boyden, E. S., Zhang, F., Bamberg, E., Nagel, G., and Deisseroth, K. (2005). Millisecond-timescale, genetically targeted optical control of neural activity. Nat. Neurosci. 8, 1263-1268. doi: 10.1038/nn1525

Burgess, N., Maguire, E. A., and O'Keefe, J. (2002). The human hippocampus and spatial and episodic memory. Neuron 35, 625-641. doi: 10.1016/S08966273(02)00830-9

Burguière, E., Arleo, A., Hojjati, M. r., Elgersma, Y., De Zeeuw, C. I., Berthoz, A., et al. (2005). Spatial navigation impairment in mice lacking cerebellar LTD: a motor adaptation deficit? Nat. Neurosci. 8, 1292-1294. doi: 10.1038/nn1532

Bush, D., and Burgess, N. (2014). A hybrid oscillatory interference/continuous attractor network model of grid cell firing. J. Neurosci. 34, 5065-5079. doi: 10.1523/JNEUROSCI.4017-13.2014

Buzsaki, G. (2002). Theta oscillations in the hippocampus. Neuron 33, 325-340. doi: 10.1016/S0896-6273(02)00586-X

Canto, C. B., Wouterlood, F. G., and Witter, M. P. (2008). What does the anatomical organization of the entorhinal cortex tell us? Neural Plast. 2008:381243. doi: $10.1155 / 2008 / 381243$

Chkhenkeli, S. A., Sramka, M., Lortkipanidze, G. S., Rakviashvili, T. N., Bregvadze, E. S., Magalashvili, G. E., et al. (2004). Electrophysiological effects and clinical results of direct brain stimulation for intractable epilepsy. Clin. Neurol. Neurosurg. 106, 318-329. doi: 10.1016/j.clineuro.2004.01.009

Clark, G. A., McCormick, D. A., Lavond, D. G., and Thompson, R. F. (1984). Effects of lesions of cerebellar nuclei on conditioned behavioral and hippocampal neuronal responses. Brain Res. 291, 125-136. doi: 10.1016/00068993(84)90658-9
Clark, R. E., Manns, J. R., and Squire, L. R. (2002). Classical conditioning, awareness, and brain systems. Trends Cogn. Sci. 6, 524-531. doi: 10.1016/S13646613(02)02041-7

Clark, R. E., and Squire, L. R. (1998). Classical conditioning and brain systems: the role of awareness. Science 280, 77-81. doi: 10.1126/science.280.5360.77

Clower, D. M., Dum, R. P., and Strick, P. L. (2005). Basal ganglia and cerebellar inputs to 'AIP'. Cereb. Cortex 15, 913-920. doi: 10.1093/cercor/bhh190

Collin, G., Hulshoff Pol, H. E., Haijma, S. V., Cahn, W., Kahn, R. S., and van den Heuvel, M. P. (2011). Impaired cerebellar functional connectivity in schizophrenia patients and their healthy siblings. Front. Psychiatry 2:73. doi: 10.3389/fpsyt.2011.00073

Cooke, P. M., and Snider, R. S. (1955). Some cerebellar influences on electrically-induced cerebral seizures. Epilepsia 4, 19-28. doi: 10.1111/j.15281157.1955.tb03170.x

Cooper, I. S. (1973). Effect of stimulation of posterior cerebellum on neurological disease. Lancet 1, 1321. doi: 10.1016/s0140-6736(73)91338-x

Cooper, I. S., Amin, I., and Gilman, S. (1973). The effect of chronic cerebellar stimulation upon epilepsy in man. Trans. Am. Neurol. Assoc. 98, 192-196.

Cooper, I. S., Amin, I., Riklan, M., Waltz, J. M., and Poon, T. P. (1976). Chronic cerebellar stimulation in epilepsy. Clinical and anatomical studies. Arch. Neurol. 33, 559-570. doi: 10.1001/archneur.1976.00500080037006

Davis, R., and Emmonds, S. E. (1992). Cerebellar stimulation for seizure control: 17-year study. Stereotact. Funct. Neurosurg. 58, 200-208. doi: $10.1159 / 000098996$

Deisseroth, K. (2011). Optogenetics. Nat. Methods 8, 26-29. doi: 10.1038/nmeth.f.324

De Zeeuw, C. I., and Yeo, C. H. (2005). Time and tide in cerebellar memory formation. Curr. Opin. Neurobiol. 15, 667-674. doi: 10.1016/j.conb.2005.10.008

Dietrichs, E., and Haines, D. E. (1984). Demonstration of hypothalamocerebellar and cerebello-hypothalamic fibres in a prosimian primate (Galago crassicaudatus). Anat. Embryol. 170, 313-318. doi: 10.1007/BF00318735

Dietrichs, E., and Haines, D. E. (1986). Do the same hypothalamic neurons project to both amygdala and cerebellum? Brain Res. 364, 241-248. doi: 10.1016/00068993(86)90836-X

Dietrichs, E., and Haines, D. E. (1989). Interconnections between hypothalamus and cerebellum. Anat. Embryol. 179, 207-220. doi: 10.1007/BF00326585

Duan, H. F., Gan, J. L., Yang, J. M., Cheng, Z. X., Gao, C. Y., Shi, Z. J., et al. (2015). A longitudinal study on intrinsic connectivity of hippocampus associated with positive symptom in first-episode schizophrenia. Behav. Brain Res. 283, 78-86. doi: 10.1016/j.bbr.2015.01.022

Dumont, J. R., and Taube, J. S. (2015). The neural correlates of navigation beyond the hippocampus. Prog. Brain Res. 219, 83-102. doi: 10.1016/bs.pbr.2015.03.004

Eichenbaum, H. (2000). Hippocampus: mapping or memory? Curr. Biol. 10, R785-R787. doi: 10.1016/S0960-9822(00)00763-6

Eichenbaum, H. (2001). The hippocampus and declarative memory: cognitive mechanisms and neural codes. Behav. Brain Res. 127, 199-207. doi: $10.1016 /$ S0166-4328(01)00365-5

Eichenbaum, H. (2014). Time cells in the hippocampus: a new dimension for mapping memories. Nature reviews. Neuroscience 15, 732-744. doi: $10.1038 / \mathrm{nrn} 3827$

Elisevich, K. V., Hrycyshyn, A. W., and Flumerfelt, B. A. (1985). Cerebellar, medullary and spinal afferent connections of the paramedian reticular nucleus in the cat. Brain Res. 332, 267-282. doi: 10.1016/0006-8993(85)90596-7

Floresco, S. B., Todd, C. L., and Grace, A. A. (2001). Glutamatergic afferents from the hippocampus to the nucleus accumbens regulate activity of ventral tegmental area dopamine neurons. J. Neurosci. 21, 4915-4922.

Fountas, K. N., Kapsalaki, E., and Hadjigeorgiou, G. (2010). Cerebellar stimulation in the management of medically intractable epilepsy: a systematic and critical review. Neurosurg. Focus 29, E8. doi: 10.3171/2010.5.FOCUS10111

French, S. J., Hailstone, J. C., and Totterdell, S. (2003). Basolateral amygdala efferents to the ventral subiculum preferentially innervate pyramidal cell dendritic spines. Brain Res. 981, 160-167. doi: 10.1016/S0006-8993(03)03017-8

Fries, P. (2005). A mechanism for cognitive dynamics: neuronal communication through neuronal coherence. Trends Cogn. Sci. 9, 474-480. doi: 10.1016/j.tics.2005.08.011

Glickstein, M. (2007). What does the cerebellum really do? Curr. Biol. 17, R824R827. doi: 10.1016/j.cub.2007.08.009 
Gruart, A., and Yeo, C. H. (1995). Cerebellar cortex and eyeblink conditioning: bilateral regulation of conditioned responses. Exp. Brain Res. 104, 431-448. doi: 10.1007/BF00231978

Hales, J. B., Schlesiger, M. I., Leutgeb, J. K., Squire, L. R., Leutgeb, S., and Clark, R. E. (2014). Medial entorhinal cortex lesions only partially disrupt hippocampal place cells and hippocampus-dependent place memory. Cell Rep. 9, 893-901. doi: 10.1016/j.celrep.2014.10.009

Haroian, A. J., Massopust, L. C., and Young, P. A. (1981). Cerebellothalamic projections in the rat: an autoradiographic and degeneration study. J. Comp. Neurol. 197, 217-236. doi: 10.1002/cne.901970205

Harper, J. W., and Heath, R. G. (1973). Anatomic connections of the fastigial nucleus to the rostral forebrain in the cat. Exp. Neurol. 39, 285-292. doi: 10.1016/0014-4886(73)90231-8

Harvey, A. S., Jayakar, P., Duchowny, M., Resnick, T., Prats, A., Altman, N., et al. (1996). Hemifacial seizures and cerebellar ganglioglioma: an epilepsy syndrome of infancy with seizures of cerebellar origin. Ann. Neurol. 40, 91-98. doi: 10.1002/ana.410400115

Heath, R. G., Dempesy, C. W., Fontana, C. J., and Myers, W. A. (1978). Cerebellar stimulation: effects on septal region, hippocampus, and amygdala of cats and rats. Biol. Psychiatry 13, 501-529.

Heath, R. G., and Harper, J. W. (1974). Ascending projections of the cerebellar fastigial nucleus to the hippocampus, amygdala, and other temporal lobe sites: evoked potential and histological studies in monkeys and cats. Exp. Neurol. 45, 268-287. doi: 10.1016/0014-4886(74)90118-6

Hilber, P., Jouen, F., Delhaye-Bouchaud, N., Mariani, J., and Caston, J. (1998). Differential roles of cerebellar cortex and deep cerebellar nuclei in learning and retention of a spatial task: studies in intact and cerebellectomized lurcher mutant mice. Behav. Genet. 28, 299-308. doi: 10.1023/A:1021675514883

Hitier, M., Besnard, S., and Smith, P. F. (2014). Vestibular pathways involved in cognition. Front. Integr. Neurosci. 8:59. doi: 10.3389/fnint.2014.00059

Hoffmann, L. C., and Berry, S. D. (2009). Cerebellar theta oscillations are synchronized during hippocampal theta-contingent trace conditioning. Proc. Natl. Acad. Sci. U.S.A. 106, 21371-21376. doi: 10.1073/pnas.0908403106

Hoffmann, L. C., Cicchese, J. J., and Berry, S. D. (2015). Harnessing the power of theta: natural manipulations of cognitive performance during hippocampal theta-contingent eyeblink conditioning. Front. Syst. Neurosci. 9:50. doi: 10.3389/fnsys.2015.00050

Igloi, K., Doeller, C. F., Paradis, A. L., Benchenane, K., Berthoz, A., Burgess, N., et al. (2014). Interaction between hippocampus and cerebellum crus I in sequence-based but not place-based navigation. Cereb. Cortex 25, 4146-4154. doi: 10.1093/cercor/bhu132

Ishikawa, A., and Nakamura, S. (2006). Ventral hippocampal neurons project axons simultaneously to the medial prefrontal cortex and amygdala in the rat. J. Neurophysiol. 96, 2134-2138. doi: 10.1152/jn.00069.2006

Ito, M. (1982). Questions in modeling the cerebellum. J. Theor. Biol. 99, 81-86. doi: 10.1016/0022-5193(82)90390-3

Kahn, I., and Shohamy, D. (2013). Intrinsic connectivity between the hippocampus, nucleus accumbens, and ventral tegmental area in humans. Hippocampus 23, 187-192. doi: 10.1002/hipo.22077

Kandel, A., and Buzsáki, G. (1993). Cerebellar neuronal activity correlates with spike and wave EEG patterns in the rat. Epilepsy Res. 16, 1-9. doi: 10.1016/09201211(93)90033-4

Kawamura, K., and Hashikawa, T. (1981). Projections from the pontine nuclei proper and reticular tegmental nucleus onto the cerebellar cortex in the cat. An autoradiographic study. J. Comp. Neurol. 201, 395-413. doi: $10.1002 /$ cne. 902010307

Kim, J. J., Clark, R. E., and Thompson, R. F. (1995). Hippocampectomy impairs the memory of recently, but not remotely, acquired trace eyeblink conditioned responses. Behav. Neurosci. 109, 195-203. doi: 10.1037/0735-7044.109.2.195

Kirsch, P., Achenbach, C., Kirsch, M., Heinzmann, M., Schienle, A., and Vaitl, D. (2003). Cerebellar and hippocampal activation during eyeblink conditioning depends on the experimental paradigm: a MEG study. Neural Plast. 10, 291-301. doi: 10.1155/NP.2003.291

Kohler, C., and Steinbusch, H. (1982). Identification of serotonin and non-serotonin-containing neurons of the mid-brain raphe projecting to the entorhinal area and the hippocampal formation. A combined immunohistochemical and fluorescent retrograde tracing study in the rat brain. Neuroscience 7, 951-975. doi: 10.1016/0306-4522(82)90054-9
Krook-Magnuson, E., Armstrong, C., Bui, A., Lew, S., Oijala, M., and Soltesz, I. (2015a). In vivo evaluation of the dentate gate theory in epilepsy. J. Physiol. 593, 2379-2388. doi: 10.1113/JP270056

Krook-Magnuson, E., Armstrong, C., Oijala, M., and Soltesz, I. (2013). On-demand optogenetic control of spontaneous seizures in temporal lobe epilepsy. Nat. Commun. 4, 1376. doi: 10.1038/ncomms2376

Krook-Magnuson, E., Gelinas, J. N., Soltesz, I., and Buzsáki, G. (2015b). Neuroelectronics and biooptics: closed-loop technologies in neurological disorders. JAMA Neurol. 72, 823-829. doi: 10.1001/jamaneurol. 2015.0608

Krook-Magnuson, E., and Soltesz, I. (2015). Beyond the hammer and the scalpel: selective circuit control for the epilepsies. Nat. Neurosci. 18, 331-338. doi: 10.1038/nn.3943

Krook-Magnuson, E., Szabo, G. G., Armstrong, C., Oijala, M., and Soltesz, I. (2014). Cerebellar directed optogenetic intervention inhibits spontaneous hippocampal seizures in a mouse model of temporal lobe epilepsy. eNeuro 1:e.2014. doi: 10.1523/ENEURO.0005-14.2014

Kros, L., Eelkman Rooda, O. H., Spanke, J. K., Alva, P., van Dongen, M. N., Karapatis, A., et al. (2015). Cerebellar output controls generalized spike-and-wave discharge occurrence. Ann. Neurol. 77, 1027-1049. doi: 10.1002/ana.24399

Küper, M., Kaschani, P., Thürling, M., Stefanescu, M. R., Burciu, R. G., Göricke, S., et al. (2015). Cerebellar fMRI activation increases with increasing working memory demands. Cerebellum. doi: 10.1007/s12311-015-0703-7. [Epub ahead of print].

Lalonde, R., and Botez, M. I. (1990). The cerebellum and learning processes in animals. Brain research. Brain Res. Rev. 15, 325-332. doi: 10.1016/01650173(90)90006-A

Leifer, D., Cole, D. G., and Kowall, N. W. (1991). Neuropathologic asymmetries in the brain of a patient with a unilateral status epilepticus. J. Neurol. Sci. 103 , 127-135. doi: 10.1016/0022-510X(91)90155-Z

Leiner, H. C., Leiner, A. L., and Dow, R. S. (1986). Does the cerebellum contribute to mental skills? Behav. Neurosci. 100, 443-454. doi: 10.1037/07357044.100.4.443

Leiner, H. C., Leiner, A. L., and Dow, R. S. (1989). Reappraising the cerebellum: what does the hindbrain contribute to the forebrain? Behav. Neurosci. 103, 998-1008. doi: 10.1037/0735-7044.103.5.998

Levy, L. F., and Auchterlonie, W. C. (1979). Chronic cerebellar stimulation in the treatment of epilepsy. Epilepsia 20, 235-245. doi: 10.1111/j.15281157.1979.tb04800.x

Lewis, P. R., and Shute, C. C. (1967). The cholinergic limbic system: projections to hippocampal formation, medial cortex, nuclei of the ascending cholinergic reticular system, and the subfornical organ and supra-optic crest. Brain 90 , 521-540. doi: 10.1093/brain/90.3.521

Lima, F. F., Sita, L. V., Oliveira, A. R., Costa, H. C., da Silva, J. M., Mortara, R. A., et al. (2013). Hypothalamic melanin-concentrating hormone projections to the septo-hippocampal complex in the rat. J. Chem. Neuroanat. 47, 1-14. doi: 10.1016/j.jchemneu.2012.10.003

Liu, W., Zhang, Y., Yuan, W., Wang, J., and Li, S. (2012). A direct hippocampo-cerebellar projection in chicken. Anat. Rec. 295, 1311-1320. doi: $10.1002 /$ ar.22515

Logan, C. G., and Grafton, S. T. (1995). Functional anatomy of human eyeblink conditioning determined with regional cerebral glucose metabolism and positron-emission tomography. Proc. Natl. Acad. Sci. U.S.A. 92, 7500-7504. doi: 10.1073/pnas.92.16.7500

Longley, M., and Yeo, C. H. (2014). Distribution of neural plasticity in cerebellumdependent motor learning. Prog. Brain Res. 210, 79-101. doi: 10.1016/B978-0444-63356-9.00004-2

Luo, Y., and Sugihara, I. (2014). Cerebellar afferents originating from the medullary reticular formation that are different from mossy, climbing or monoaminergic fibers in the rat. Brain Res. 1566, 31-46. doi: 10.1016/j.brainres.2014.04.020

MacDonald, C. J., Lepage, K. Q., Eden, U. T., and Eichenbaum, H. (2011) Hippocampal "time cells" bridge the gap in memory for discontiguous events. Neuron 71, 737-749. doi: 10.1016/j.neuron.2011.07.012

Maiti, A., and Snider, R. S. (1975). Cerebellar control of basal forebrain seizures: amygdala and hippocampus. Epilepsia 16, 521-533. doi: 10.1111/j.1528 1157.1975.tb06082.x 
Manto, M., Bower, J. M., Conforto, A. B., Delgado-García, J. M., da Guarda, S. N., Gerwig, M., et al. (2012). Consensus paper: roles of the cerebellum in motor control-the diversity of ideas on cerebellar involvement in movement. Cerebellum 11, 457-487. doi: 10.1007/s12311-011-0331-9

Mark, M. D., Maejima, T., Kuckelsberg, D., Yoo, J. W., Hyde, R. A., Shah, V., et al. (2011). Delayed postnatal loss of P/Q-type calcium channels recapitulates the absence epilepsy, dyskinesia, and ataxia phenotypes of genomic Cacnala mutations. J. Neurosci. 31, 4311-4326. doi: 10.1523/JNEUROSCI.534210.2011

Matano, S. (2001). Brief communication: Proportions of the ventral half of the cerebellar dentate nucleus in humans and great apes. Am. J. Phys. Anthropol. 114, 163-165. doi: 10.1002/1096-8644(200102)114:2<163::AIDAJPA1016>3.0.CO;2-F

Mauk, M. D., and Thompson, R. F. (1987). Retention of classically conditioned eyelid responses following acute decerebration. Brain Res. 403, 89-95. doi: 10.1016/0006-8993(87)90126-0

McCartney, H., Johnson, A. D., Weil, Z. M., and Givens, B. (2004). Theta reset produces optimal conditions for long-term potentiation. Hippocampus 14, 684-687. doi: 10.1002/hipo.20019

McGlinchey-Berroth, R., Carrillo, M. C., Gabrieli, J. D., Brawn, C. M., and Disterhoft, J. F. (1997). Impaired trace eyeblink conditioning in bilateral, medial-temporal lobe amnesia. Behav. Neurosci. 111, 873-882. doi: 10.1037/0735-7044.111.5.873

McNaughton, B. L., Battaglia, F. P., Jensen, O., Moser, E. I., and Moser, M. B. (2006). Path integration and the neural basis of the 'cognitive map'. Nature reviews. Neuroscience 7, 663-678. doi: 10.1038/nrn1932

Mesiwala, A. H., Kuratani, J. D., Avellino, A. M., Roberts, T. S., Sotero, M. A., and Ellenbogen, R. G. (2002). Focal motor seizures with secondary generalization arising in the cerebellum. Case report and review of the literature. J. Neurosurg. 97, 190-196. doi: 10.3171/jns.2002.97.1.0190

Miller, J. W. (1992). The role of mesencephalic and thalamic arousal systems in experimental seizures. Progr. Neurobiol. 39, 155-178. doi: 10.1016/03010082(92)90009-4

Mitra, J., and Snider, R. S. (1975). Effects of hippocampal afterdischarges on Purkinje cell activity. Epilepsia 16, 235-243. doi: 10.1111/j.15281157.1975.tb06053.x

Moyer, J. R. Jr., Deyo, R. A., and Disterhoft, J. F. (1990). Hippocampectomy disrupts trace eye-blink conditioning in rabbits. Behav. Neurosci. 104, 243-252. doi: 10.1037/0735-7044.104.2.243

Newman, P. P., and Reza, H. (1979). Functional relationships between the hippocampus and the cerebellum: an electrophysiological study of the cat. J. Physiol. 287, 405-426. doi: 10.1113/jphysiol.1979.sp012667

Nokia, M. S., Sisti, H. M., Choksi, M. R., and Shors, T. J. (2012). Learning to learn: theta oscillations predict new learning, which enhances related learning and neurogenesis. PLOS ONE 7:e31375. doi: 10.1371/journal.pone. 0031375

Oades, R. D., and Halliday, G. M. (1987). Ventral tegmental (A10) system: neurobiology. 1. Anatomy and connectivity. Brain Res. 434, 117-165. doi: 10.1016/0165-0173(87)90011-7

Ohara, S., Sato, S., Tsutsui, K., Witter, M. P., and Iijima, T. (2013). Organization of multisynaptic inputs to the dorsal and ventral dentate gyrus: retrograde transsynaptic tracing with rabies virus vector in the rat. PLOS ONE 8:e78928. doi: 10.1371/journal.pone.0078928

Onat, F., and Cavdar, S. (2003). Cerebellar connections: hypothalamus. Cerebellum 2, 263-269. doi: 10.1080/14734220310016187

Onuki, Y., Van Someren, E. J., De Zeeuw, C. I., and Van der Werf, Y. D. (2015). Hippocampal-cerebellar interaction during spatio-temporal prediction. Cereb. Cortex 25, 313-321. doi: 10.1093/cercor/bht221

Paleja, M., Girard, T. A., Herdman, K. A., and Christensen, B. K. (2014). Two distinct neural networks functionally connected to the human hippocampus during pattern separation tasks. Brain Cogn. 92C, 101-111. doi: 10.1016/j.bandc.2014.10.009

Passot, J. B., Sheynikhovich, D., Duvelle, É., and Arleo, A. (2012). Contribution of cerebellar sensorimotor adaptation to hippocampal spatial memory. PLoS ONE 7:e32560. doi: 10.1371/journal.pone.0032560

Paul, S. M., Heath, R. G., and Ellison, J. P. (1973). Histochemical demonstration of a direct pathway from the fastigial nucleus to the septal region. Exp. Neurol. 40, 798-805. doi: 10.1016/0014-4886(73)90113-1
Perciavalle, V., Berretta, S., and Raffaele, R. (1989). Projections from the intracerebellar nuclei to the ventral midbrain tegmentum in the rat. Neuroscience 29, 109-119. doi: 10.1016/0306-4522(89)90336-9

Person, R. J., Andrezik, J. A., Dormer, K. J., and Foreman, R. D. (1986a). Fastigial nucleus projections in the midbrain and thalamus in dogs. Neuroscience 18, 105-120. doi: 10.1016/0306-4522(86)90182-X

Person, R. J., Dormer, K. J., Bedford, T. G., Andrezik, J. A., and Foreman, R. D. (1986b). Fastigial nucleus modulation of medullary parasolitary neurons. Neuroscience 19, 1293-1301. doi: 10.1016/0306-4522(86) 90143-0

Petrosini, L., Leggio, M. G., and Molinari, M. (1998). The cerebellum in the spatial problem solving: a co-star or a guest star? Progr. Neurobiol. 56, 191-210. doi: 10.1016/S0301-0082(98)00036-7

Phillips, J. R., Hewedi, D. H., Eissa, A. M., and Moustafa, A. A. (2015). The cerebellum and psychiatric disorders. Front. Public Health 3:66. doi: 10.3389/fpubh.2015.00066

Pierce, E. T., Hoddevik, G. H., and Walberg, F. (1977). The cerebellar projection from the raphe nuclei in the cat as studied with the method of retrograde transport of horseradish peroxidase. Anat. Embryol. 152, 73-87. doi: 10.1007/BF00341436

Popa, L. S., Hewitt, A. L., and Ebner, T. J. (2014). The cerebellum for jocks and nerds alike. Front. Syst. Neurosci. 8:113. doi: 10.3389/fnsys.2014.00113

Ravassard, P., Kees, A., Willers, B., Ho, D., Aharoni, D., Cushman, J., et al. (2013). Multisensory control of hippocampal spatiotemporal selectivity. Science 340, 1342-1346. doi: 10.1126/science. 1232655

Rochefort, C., Arabo, A., André, M., Poucet, B., Save, E., and Rondi-Reig, L. (2011). Cerebellum shapes hippocampal spatial code. Science 334, 385-389. doi: $10.1126 /$ science. 1207403

Rochefort, C., Lefort, J. M., and Rondi-Reig, L. (2013). The cerebellum: a new key structure in the navigation system. Front. Neural Circuits 7:35. doi: 10.3389 /fncir. 2013.00035

Ryou, J. W., Cho, S. Y., and Kim, H. T. (1998). Lesion of the cerebellar interpositus nucleus or the red nucleus affects classically conditioned neuronal activity in the hippocampus. Prog. Neuropsychopharmacol. Biol. Psychiatry 22, 169-185. doi: 10.1016/S0278-5846(97)00187-5

Salvatierra, A. T., and Berry, S. D. (1989). Scopolamine disruption of septohippocampal activity and classical conditioning. Behav. Neurosci. 103, 715-721. doi: 10.1037/0735-7044.103.4.715

Sears, L. L., Logue, S. F., and Steinmetz, J. E. (1996). Involvement of the ventrolateral thalamic nucleus in rabbit classical eyeblink conditioning. Behav. Brain Res. 74, 105-117. doi: 10.1016/0166-4328(96)00171-4

Sears, L. L., and Steinmetz, J. E. (1990). Acquisition of classically conditionedrelated activity in the hippocampus is affected by lesions of the cerebellar interpositus nucleus. Behav. Neurosci. 104, 681-692. doi: 10.1037/07357044.104.5.681

Singer, W. (1999). Neuronal synchrony: a versatile code for the definition of relations? Neuron 24, 111-125. doi: 10.1016/S0896-6273(00)80821-1

Snider, R. S., and Maiti, A. (1976). Cerebellar contributions to the Papez circuit. J. Neurosci. Res. 2, 133-146. doi: 10.1002/jnr.490020204

Snider, R. S., Maiti, A., and Snider, S. R. (1976). Cerebellar connections to catecholamine systems: anatomical and biochemical studies. Trans. Am. Neurol. Assoc. 101, 295-297.

Soffer, D., Melamed, E., Assaf, Y., and Cotev, S. (1986). Hemispheric brain damage in unilateral status epilepticus. Ann. Neurol. 20, 737-740. doi: 10.1002/ana.410200616

Solomon, P. R., Groccia-Ellison, M. E., Flynn, D., Mirak, J., Edwards, K. R. Dunehew, A., et al. (1993). Disruption of human eyeblink conditioning after central cholinergic blockade with scopolamine. Behav. Neurosci. 107, 271-279. doi: 10.1037/0735-7044.107.2.271

Solomon, P. R., Solomon, S. D., Schaaf, E. V., and Perry, H. E. (1983). Altered activity in the hippocampus is more detrimental to classical conditioning than removing the structure. Science 220, 329-331. doi: 10.1126/science.6836277

Solomon, P. R., Vander Schaaf, E. R., Thompson, R. F., and Weisz, D. J. (1986). Hippocampus and trace conditioning of the rabbit's classically conditioned nictitating membrane response. Behav. Neurosci. 100, 729-744. doi: 10.1037/0735-7044.100.5.729

Soussi, R., Boulland, J. L., Bassot, E., Bras, H., Coulon, P., Chaudhry, F. A., et al. (2015). Reorganization of supramammillary-hippocampal 
pathways in the rat pilocarpine model of temporal lobe epilepsy: evidence for axon terminal sprouting. Brain Struct. Funct. 220, 2449-2468. doi: 10.1007/s00429-014-0800-2

Sramka, M., Fritz, G., Galanda, M., and Nádvornik, P. (1976). Some observations in treatment stimulation of epilepsy. Acta Neurochirurgica 23(Suppl), 257-262.

Strick, P. L., Dum, R. P., and Fiez, J. A. (2009). Cerebellum and nonmotor function. Ann. Rev. Neurosci. 32, 413-434. doi: 10.1146/annurev.neuro.31.060407.125606

Swanson, L. W., and Cowan, W. M. (1977). An autoradiographic study of the organization of the efferent connections of the hippocampal formation in the rat. J. Comp. Neurol. 172, 49-84. doi: 10.1002/cne.901720104

Takehara, K., Kawahara, S., and Kirino, Y. (2003). Time-dependent reorganization of the brain components underlying memory retention in trace eyeblink conditioning. J. Neurosci. 23, 9897-9905.

Takehara, K., Kawahara, S., Takatsuki, K., and Kirino, Y. (2002). Time-limited role of the hippocampus in the memory for trace eyeblink conditioning in mice. Brain Res. 951, 183-190. doi: 10.1016/S0006-8993(02)03159-1

Tan, N., and Urich, H. (1984). Postictal cerebral hemiatrophy: with a contribution to the problem of crossed cerebellar atrophy. Acta Neuropathol. 62, 332-339. doi: $10.1007 / \mathrm{BF} 00687616$

Taube, J. S. (2007). The head direction signal: origins and sensorymotor integration. Ann. Rev. Neurosci. 30, 181-207. doi: 10.1146/ annurev.neuro.29.051605.112854

Taylor, J. A., and Ivry, R. B. (2014). Cerebellar and prefrontal cortex contributions to adaptation, strategies, and reinforcement learning. Prog. Brain Res. 210, 217-253. doi: 10.1016/B978-0-444-63356-9.00009-1

Teune, T. M., van der Burg, J., van der Moer, J., Voogd, J., and Ruigrok, T. J. (2000). Topography of cerebellar nuclear projections to the brain stem in the rat. Prog. Brain Res. 124, 141-172. doi: 10.1016/S0079-6123(00)24014-4

Thompson, R. F., and Krupa, D. J. (1994). Organization of memory traces in the mammalian brain. Ann. Rev. Neurosci. 17, 519-549. doi: 10.1146/annurev.ne.17.030194.002511

Thompson, R. F., and Steinmetz, J. E. (2009). The role of the cerebellum in classical conditioning of discrete behavioral responses. Neuroscience 162, 732-755. doi: 10.1016/j.neuroscience.2009.01.041

Van Buren, J. M., Wood, J. H., Oakley, J., and Hambrecht, F. (1978). Preliminary evaluation of cerebellar stimulation by double-blind stimulation and biological criteria in the treatment of epilepsy. J. Neurosurg. 48, 407-416. doi: 10.3171/jns.1978.48.3.0407

Velasco, F., Carrillo-Ruiz, J. D., Brito, F., Velasco, M., Velasco, A. L., Marquez, I., et al. (2005). Double-blind, randomized controlled pilot study of bilateral cerebellar stimulation for treatment of intractable motor seizures. Epilepsia 46, 1071-1081. doi: 10.1111/j.1528-1167.2005.70504.x

Vertes, R. P. (2015). Major diencephalic inputs to the hippocampus: supramammillary nucleus and nucleus reuniens. Circuitry and function. Prog. Brain Res. 219, 121-144. doi: 10.1016/bs.pbr.2015.03.008
Verveer, C., Hawkins, R. K., Ruigrok, T. J., and De Zeeuw, C. I. (1997) Ultrastructural study of the GABAergic and cerebellar input to the nucleus reticularis tegmenti pontis. Brain Res. 766, 289-296. doi: 10.1016/S00068993(97)00774-9

Wallesch, C. W., and Horn, A. (1990). Long-term effects of cerebellar pathology on cognitive functions. Brain Cogn. 14, 19-25. doi: 10.1016/0278-2626(90) 90057-U

Weaver, A. H. (2005). Reciprocal evolution of the cerebellum and neocortex in fossil humans. Proc. Natl. Acad. Sci. U.S.A. 102, 3576-3580. doi: 10.1073/pnas.0500692102

Weiss, C., Bouwmeester, H., Power, J. M., and Disterhoft, J. F. (1999). Hippocampal lesions prevent trace eyeblink conditioning in the freely moving rat. Behav. Brain Res. 99, 123-132. doi: 10.1016/S0166-4328(98) 00096-5

Weiss, C., and Disterhoft, J. F. (2011). Exploring prefrontal cortical memory mechanisms with eyeblink conditioning. Behav. Neurosci. 125, 318-326. doi: 10.1037/a0023520

Weiss, C., and Disterhoft, J. F. (2015). The impact of hippocampal lesions on traceeyeblink conditioning and forebrain-cerebellar interactions. Behav. Neurosci. 129, 512-522. doi: 10.1037/bne0000061

Wiebe, S. (2000). Epidemiology of temporal lobe epilepsy. Can. J. Neurol. Sci. 27 (Suppl. 1), S6-S10; discussion S20-S21. doi: 10.1017/s03171671000 00561

Wikgren, J., Nokia, M. S., and Penttonen, M. (2010). Hippocampo-cerebellar theta band phase synchrony in rabbits. Neuroscience 165, 1538-1545. doi: 10.1016/j.neuroscience.2009.11.044

Wright, G. D., McLellan, D. L., and Brice, J. G. (1984). A double-blind trial of chronic cerebellar stimulation in twelve patients with severe epilepsy. J. Neurol. Neurosurg. Psychiatr. 47, 769-774. doi: 10.1136/jnnp. 47.8.769

Yakusheva, T. A., Shaikh, A. G., Green, A. M., Blazquez, P. M., Dickman, J. D., and Angelaki, D. E. (2007). Purkinje cells in posterior cerebellar vermis encode motion in an inertial reference frame. Neuron 54, 973-985. doi: 10.1016/j.neuron.2007.06.003

Conflict of Interest Statement: The authors declare that the research was conducted in the absence of any commercial or financial relationships that could be construed as a potential conflict of interest.

Copyright (c) $2015 \mathrm{Yu}$ and Krook-Magnuson. This is an open-access article distributed under the terms of the Creative Commons Attribution License (CC BY). The use, distribution or reproduction in other forums is permitted, provided the original author(s) or licensor are credited and that the original publication in this journal is cited, in accordance with accepted academic practice. No use, distribution or reproduction is permitted which does not comply with these terms. 